\title{
Effect of temperature on rheological properties of lithium-based
}

\section{magnetorheological grease}

\author{
Huixing Wang ${ }^{1}$, Yancheng $\mathrm{Li}^{2}, 3$, Guang Zhang ${ }^{1}$, Jiong Wang ${ }^{1}$ \\ 1. School of Mechanical Engineering, Nanjing University of Science and Technology, Nanjing 210094, People’s \\ Republic of China \\ 2. School of Civil and Environmental Engineering, University of Technology Sydney, Ultimo 2007, Australia \\ 3. College of Civil Engineering, Nanjing Tech University, Nanjing 211800, People’s Republic of China \\ Corresponding author: wjiongz@njust.edu.cn; yancheng.li@uts.edu.au
}

\begin{abstract}
\end{abstract}
This paper investigates the impact of temperature on the rheological properties of magnetorheological (MR) grease containing carbonyl iron suspended in lithium-based grease within the temperature range from $10^{\circ} \mathrm{C}$ to $70^{\circ} \mathrm{C}$ under influence of temperature, i.e. from $10^{\circ} \mathrm{C}$ to $70^{\circ} \mathrm{C}$. Lithium-based MR grease with $70 \%$ weight fraction of carbonyl iron has beenis firstly prepared by mechanical mixing. The apparent viscosity and shear stress as a function of shear rate under different temperatures and magnetic field strengths are measured and discussed. It is found that the influence of temperature on apparent viscosity is reducingreduces with the increase of magnetic field strength. In addition, in the presence of magnetic field, maximum yield stress gets demonstrates an increase as temperature increases from $50^{\circ} \mathrm{C}$ to $60^{\circ} \mathrm{C}$. The dynamic properties of MR grease are obtained under oscillatory shear test. The influences of strain amplitude, driving frequency and magnetic field on the dynamic properties of MR grease at different temperature are discussed. The results demonstrate that the enhancement of temperature leads to the increase of storage modulus and the reduction of the loss factor. Microstructural variation of grease matrix at different temperature is proposed as an explanation of the rheological changes of MR grease.

Keywords: MR grease, temperature, steady shear properties, dynamic properties, magnetic field

\section{Introduction}

MR grease is a family of smart materials with reversible rheological properties stimulated by an external magnetic field, which is generally prepared by dispersing soft magnetic particles in grease matrix $^{[1-4]}$. Unlike MR fluid ${ }^{[5-7]}$, MR grease exhibits a solid-like state in the absence of a magnetic field, which can effectively avoid the problem of settling and have simple sealing advantage. In a way, MR grease is more like MR elastomer ${ }^{[8-10]}$ but with softer matrix, which is expected to demonstrate a higher MR effect than its elastomeric brother and lower MR effect than the fluidic member. Besides, the magnetic particles in MR grease has certain freedom to move and form chain or columnar oriented structure under an external magnetic field, and the oriented microstructure can still be maintained after the magnetic field is removed. The above features show that MR grease carries the family heritage of the MR material on large MR effect while possesses little sedimentation issue, which provides a reliable and simple solution to design dampers, isolators and clutches ${ }^{[7,8,11-12]}$.

Rheological properties of MR grease under rotational and oscillatory shear have been investigated by a number of researchers. Rankin et al investigated the effect of diluted grease on
Formatted: Font: Times New Roman

Formatted: Font: (Default) Cambria Math

Formatted: Font: (Default) Cambria Math

Formatted: Font: (Default) Cambria Math

Formatted: Font: (Default) Cambria Math

Formatted: Font: (Default) Times New Roman 
the MR response. Their study found that the field-induced rheology of the suspension would not be affected if the yield stress of grease was limited to a specific range ${ }^{[13]}$. Mohamad et al prepared a series of MR grease with different content of carbonyl iron particles(CIP). The highest dynamic yield stress and the relative MR effect of MR grease in that work can reach about $52.7 \mathrm{kPa}$ and $952.38 \%$, respectively ${ }^{[14]}$. Kwon et al studied rheological properties of MR grease composed of CIP, grease and $\mathrm{CrO}_{2}$. The yield stress of the fabricated MR grease varied as $\mathrm{B}^{3 / 2}$ and has an linear relationship with particle volume fraction ${ }^{[15]}$. Park et al tested the dependence of the storage modulus $\left(G^{\prime}\right)$ and loss modulus $\left(G^{\prime \prime}\right)$ on angular frequency $(\omega)$. The results showed that both the storage and loss modulus values remain constant as the frequency increases at a fixed magnetic field, implying MR grease formed a strong solid-like structure ${ }^{[16]}$. Sahin et al investigated the effect of temperature on the shear stress responses of MR grease, and proposed a new model for yield stress ${ }^{[17-18]}$. Most of the results reported in literature were related to the properties of MR grease at an ambient temperature. However, studies on the rheological properties exhibited by MR grease under different temperature have been rarely conducted.

As known, the properties of the matrix have considerable impact on the rheological performance of MR materials. As grease matrix itself is a kind of viscoelastic material, its impact on the rheology of MR grease should be examined and properly understood. The performance of lubricating greases depends on the nature of its components and the microstructure under different operating condition ${ }^{[19-20]}$. In general, lubricating greases are highly structured colloidal dispersions consisting of a thickener dispersed in mineral or synthetic oil ${ }^{[21]}$. The thickener forms the basic skeleton structure of the grease, which can be generally divided into two types: metallic soap thickeners and non-soap thickeners. Metallic soap thickeners are prepared by saponification of a fatty acid and have a rod-like or twist-like fiber structure. Lithium 12-hydroxystearate is the most widely thickening agent used in soap-based greases, which forms an entanglement fiber network trapping the oil and conferring appropriate rheological to the grease ${ }^{[22]}$. Changes in the structure of the entanglement fiber will inevitably cause changes in the rheological properties of the grease. Temperature is one of the important factors affecting the change of entanglement fiber structure. Sanchez et al investigated the rheological characterization of lubricating greases under different temperature by using the atomic force microscopy. The results showed that the overall entanglement degree of the soap fiber decreased with the increase of temperature, resulting in the decrease of viscosity of grease $\mathrm{e}^{[23-24]}$. Martín et al found that the storage modulus $\left(G^{\prime}\right)$ decreased gradually with temperature, which is attributed to the changes in the structure of the soap fiber ${ }^{[25-27]}$. Hurley et al studied the thermal aging problem of grease at $120_{\Delta}^{\circ} \mathrm{C}$. The results proved that the soap fiber will be destroyed under long exposure in high temperature and the properties of grease will be affected ${ }^{[28-30]}$.

The above results show that the matrix of MR grease is strong temperature-dependent material. Owing to the dynamics of entanglement fiber structure of grease along temperature variations, the formation chain of particles in MR grease will be affected. In return, it will cause sustainable change in the viscosity and dynamic properties of MR grease, whether a magnetic field is applied or not. Therefore, it is of great importance to understand the field-dependent rheological characteristics of MR grease at different temperatures. In this paper, the field dependent rheological properties of MR grease were investigated within a temperature range of $10^{\circ} \mathrm{C}$ to $70^{\circ} \mathrm{C}$. The MR grease with $70 \%$ weight fraction of carbonyl iron is firstly prepared and the physical characterizations of MR grease, such as magnetic properties and microstructure, were 
measured and discussed accordingly. Then the steady-shear properties of MR grease are tested and analyzed at different temperature. Finally, the dynamic properties of MR grease are obtained under oscillatory shear. The influences of strain amplitude, driving frequency, and magnetic field on the dynamic properties of MR grease at different temperatures were discussed comprehensively.

\section{Experimental testing}

\subsection{Preparation of MR grease}

In this study, MR grease was prepared by mixing carbonyl iron particles (CI, type $\mathrm{CN}$, provided by BASF in Germany with an average radius of $6 u \mathrm{~m}$ ) into a commercial grease. Lithium-based grease (Gadus S2 V220, Shell (china) Ltd, China) with NLGI0 were used as the matrix for its with low viscosity, which would produce high MR effect. The CI particles weight fraction is chosen to be $70 \%$.

MR grease was prepared by first weighing exact quantity of the grease and placing it in a vial. The grease matrix was then stirred by a mechanical stirrer at $500 \mathrm{rpm}$ for about 10 min under the temperature of $80{ }_{\mathrm{A}}^{\circ} \mathrm{C}$. The CI particles with $70 \%$ weight fractions were added into the accommodating matrix. Finally, the mixture was stirred at $800 \mathrm{rpm}$ with the same mechanical stirrer until the grease and CI particles were fully and evenly mixed

\subsection{Properties characterization}

\subsubsection{Physical characterization}

The magnetic properties of MR grease, i.e. magnetic hysteresis loop, were measured by using the Vibrating Sample Magnetometer (VSM, Lakeshore, 7404 Series) at room temperature._

\subsubsection{Rheological characterization}

A parallel-plate rheometer (Physica MCR 302, Anton Paar Co., Austria) with magneto-controllable accessory (MRD 180) and temperature control unit (JULABO F25) was used to study the temperature-dependent rheological properties of MR grease under different field through rotational and oscillatory shear tests. In this study, a plate with a diameter of $20 \mathrm{~mm}$ is used and a gap between the plate and the base was kept at $1 \mathrm{~mm}$ throughout the experiment. MRD 180 can produces a uniform magnetic field strength in the gap from 0 to $866 \mathrm{kA} / \mathrm{m}$ by adjusting the coil current from 0 to $5 \mathrm{~A}$.

The apparent viscosity and shear stress of MR grease were measured during the rotational test under different magnetic field strengths and temperatures, with shear rate ranging from $0.1 \mathrm{~s}^{-1}$ to $100 \mathrm{~s}^{-1}$. Under oscillatory shear rheometry, the strain amplitude sweep test and the frequency sweep test were conducted at five magnetic field strengths, i.e. 0 kA/m, 193 kA/m, 391 kA/m, 740 $\mathrm{kA} / \mathrm{m}$. In strain amplitude test, the strain amplitude ranges from $0.01 \%$ to $10 \%$ at a fixed frequency $f=5 \mathrm{~Hz}$. In the frequency sweep test, the frequency varied from $1 \mathrm{~Hz}$ to $100 \mathrm{~Hz}$ at a fixed strain amplitude $\gamma=0.01 \%$. In magnetic field strength test ,a magnetic field sweep test was carried out with magnetic field strengths sweeping from 0 to $866 \mathrm{kA} / \mathrm{m}$, i.e. at a fixed strain amplitude $\gamma=0.01 \%$ and frequency $f=5 \mathrm{~Hz}$, to obtain the dynamic characteristics of MR grease. Each set of tests was carried out at $10_{\Delta}^{\circ} \mathrm{C}, 20_{\Delta}^{\circ} \mathrm{C}, 30_{\Delta}^{\circ} \mathrm{C}, 40_{\Delta}^{\circ} \mathrm{C}, 50_{\Delta}^{\circ} \mathrm{C}, 60^{\circ} \mathrm{C}$ and $70_{A}^{\circ} \mathrm{C}$, respectively. To maintain the consistency of each measurement, sample was pre-sheared for 10 seconds at shear rate of $50 \mathrm{~s}^{-1}$. In addition, all of the experiments were performed five times to ensure the reproducibility of the obtained data.
Formatted: Font: Cambria Math

Formatted: Indent: First line: $0 \mathrm{ch}$

Formatted: Indent: First line: $2 \mathrm{ch}$ 


\section{Results and discussion}

\subsection{Physical properties}

The magnetic properties of MR grease were investigated using a VSM. The obtained results are shown in Fig. 1(a). As can be seen in the figure, in the initial stage, i.e. very low magnetic field strength, the magnetic curve is perfect linear. The yielding starts around $400 \mathrm{kA} / \mathrm{m}$ and when the external magnetic field strength increases to $700 \mathrm{kA} / \mathrm{m}$, MR grease reaches a magnetic saturation state with a saturation magnetization of $170 \mathrm{emu} / \mathrm{g}$.

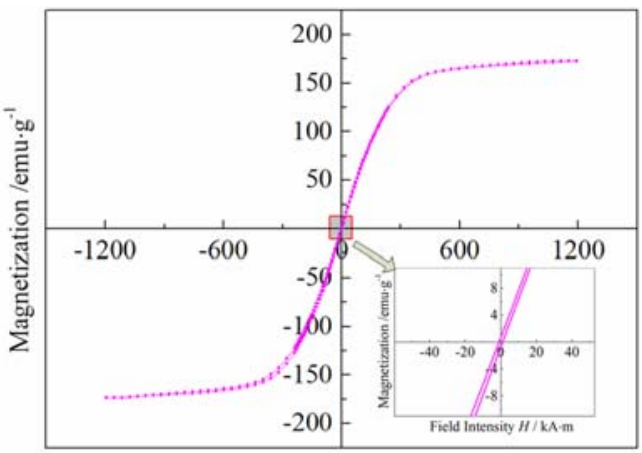

Magnetic Field Strength $H / \mathrm{kA} \cdot \mathrm{m}^{-1}$

Figure 1. magnetization curve for MR grease at room temperature

3.2 Rheology in rotational shear
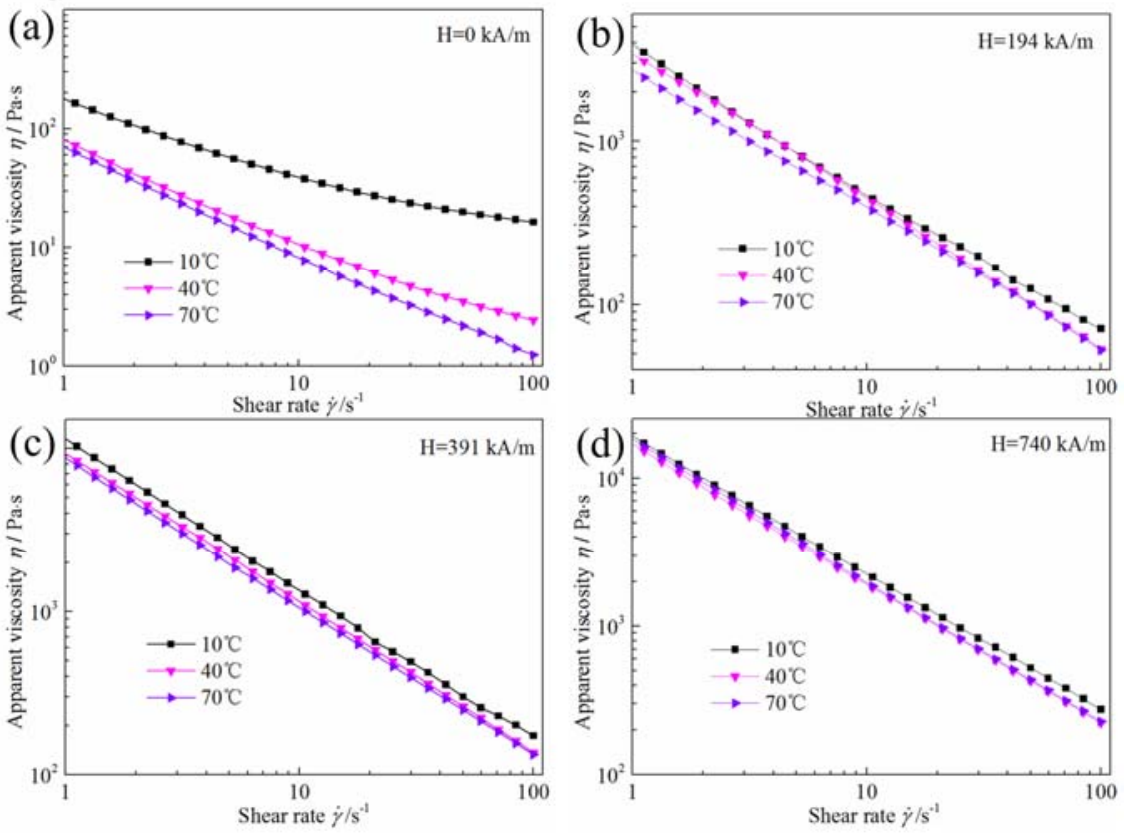

Figure 2. Apparent viscosity as a function of shear rate for MR grease under different temperatures 


\section{(a) $\mathrm{H}=0 \mathrm{kA} / \mathrm{m} ;(\mathrm{b}) \mathrm{H}=194 \mathrm{kA} / \mathrm{m} ;(\mathrm{c}) \mathrm{H}=391 \mathrm{kA} / \mathrm{m} ;(\mathrm{d}) \mathrm{H}=740 \mathrm{kA} / \mathrm{m}$}

Typical apparent viscosity curves along shear rate of the MR grease under different temperature and magnetic field strengths are shown in Figure 2. Apparent viscosity is inversely proportional to the shear rate, which is the same as that of other MR materials ${ }^{[31-32]}$. In addition, temperature affects the magnitude of the apparent viscosity under the zero-field condition. When the temperature increases from $10_{\mathrm{A}}^{\circ} \mathrm{C}$ to $70^{\circ} \mathrm{C}$, the apparent viscosity of the MR grease at the shear rate of $100 \mathrm{~s}^{-1}$ decrease from $16.4 \mathrm{~Pa}$ to $1.3 \mathrm{~Pa}$, as high as $92 \%$. This is because the apparent viscosity of MR grease is mainly dominated by the viscosity of grease matrix under the zero-field condition. In the lithium-based grease matrix, the degree of entanglement of the soap fibers rapidly decreases with the increase of temperature, resulting in a significant reduction of viscosity. From Figure 2(b), (c) and (d), it can be seen that in the presence of a magnetic field, the apparent viscosity of MR grease was only slightly affected by the temperature, and the influence became smaller and smaller with increasing magnetic field strength. The reason for this is that the apparent viscosity of MR grease was mainly determined by the friction between the CI particles and the degree of entanglement of the soap fibers at a relatively low magnetic field. With the increase of magnetic field, the friction between the CI particles gradually increases due to the stronger particle chains formed, which plays a dominant role in the viscosity of MR grease.
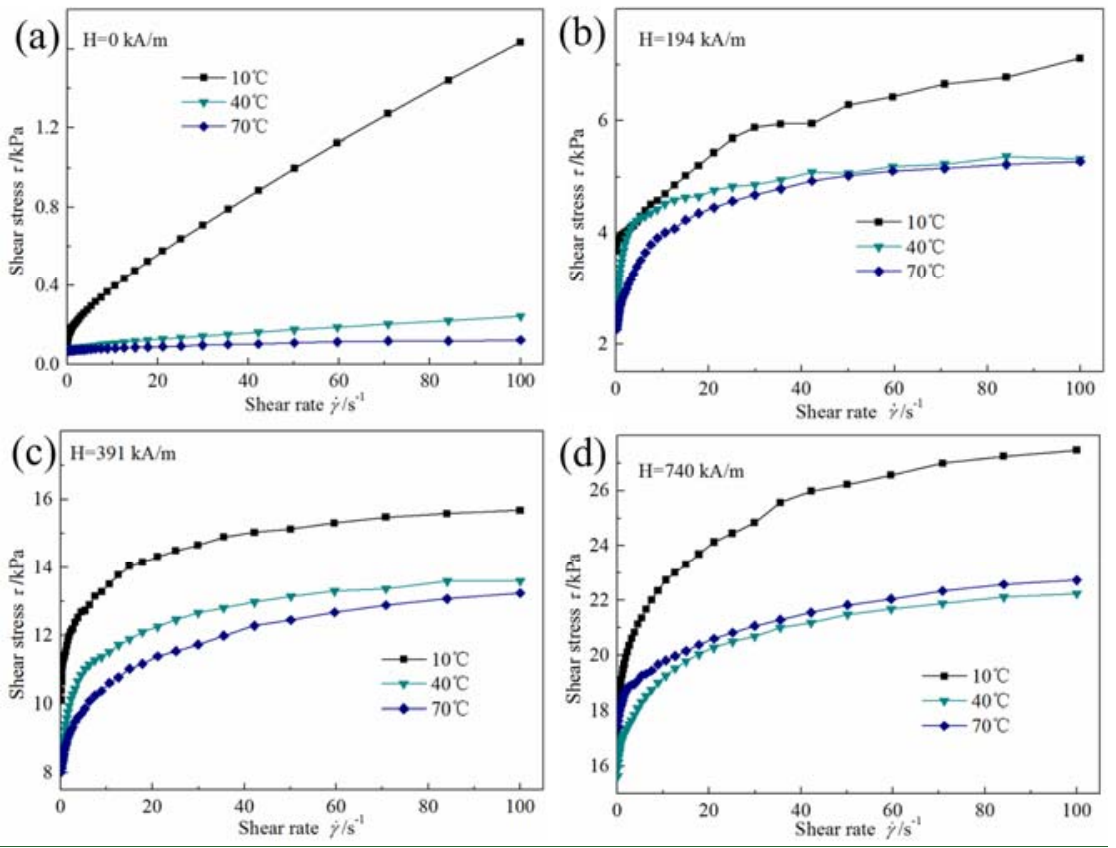

Figure 3. Shear stress versus shear rate for MR grease under different temperatures (a) $\mathrm{H}=0 \mathrm{kA} / \mathrm{m} ;(\mathrm{b}) \mathrm{H}=194 \mathrm{kA} / \mathrm{m} ;(\mathrm{c}) \mathrm{H}=391 \mathrm{kA} / \mathrm{m} ;(\mathrm{d}) \mathrm{H}=740 \mathrm{kA} / \mathrm{m}$

The shear stress versus shear rates with different temperature and applied magnetic field for the MR grease are shown in Figure 3. Shear stress increases along shear rate under different temperature, and this increase is almost linear up to $100 \mathrm{~s}^{-1}$ in the absence of magnetic field. But When the magnetic field is applied, unlike MR fluid ${ }^{[33-34]}$ that enters the stable plastic flow stage

Formatted: Font: Times New Roman
Formatted: Font: Cambria Math
Formatted: Font: Times New Roman
Formatted: Font: (Default) Cambria Math
Formatted: Font: Times New Roman


(shear stress has a linear relationship with the shear rate) immediately after yielding, there is a transition zone before the MR grease enters the stable plastic flow. The lower the temperature and the higher the magnetic field strength, the wider this transition zone becomes. This phenomenon can be explained by the typical entangled fibrous microstructures of grease matrix. In the presence of shear action, the entangled fibrous structure is gradually unwound and oriented along the shearing direction. With the increase of shear rate, MR grease gradually enters the stable plastic flow. When the temperature decreased and magnetic field strength increased, both the degree of entanglement of the soap fibers and magnetic force between CI particles increases, resulting in an increase in the transition zone of MR grease.

Another interesting phenomenon can be found from figure 3 is that, shear stress decrease along the temperature with at-magnetic field strengthapplied. of $0 \mathrm{kA} / \mathrm{m}, 193 \mathrm{kA} / \mathrm{m}, 391 \mathrm{kA} / \mathrm{m}$. But in the magnetic field strength of $740 \mathrm{kA} / \mathrm{m}$, shear stress at $70_{\mathbf{A}}^{\circ} \mathrm{C}$ is higher than that at $40^{\circ} \mathrm{C}$. The possible reason is that, in the strong external magnetic field strength and high temperature, shear stress mainly depends on the strength of the particle chain. When the temperature increase from $40_{\Delta}^{\circ} \mathrm{C}$, to $70^{\circ} \mathrm{C}$, the alignment of particles in the chain structures becomes more closely packed due to the hindrance of the grease matrix decrease, which makes the shear stress higher at $70_{\mathbf{4}}^{\circ} \mathrm{C}$.
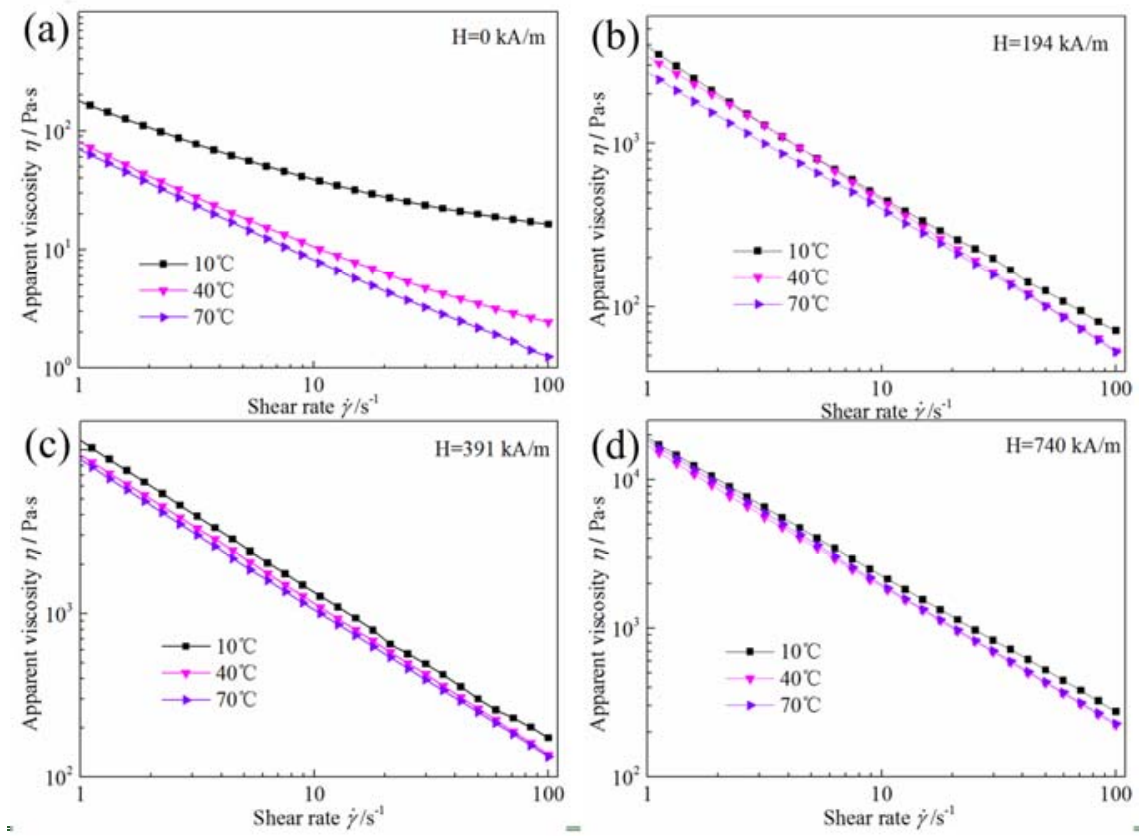

Figure 2. Apparent viseosity as a function of shear rate for MR grease under different temperatures

(a) $\mathrm{H}=0 \mathrm{kA} / \mathrm{m} ;(\mathrm{b}) \mathrm{H}=194 \mathrm{kA} / \mathrm{m} ;(\mathrm{C}) \mathrm{H}=391 \mathrm{kA} / \mathrm{m} ;(\mathrm{d}) \mathrm{H}=740 \mathrm{kA} / \mathrm{m}$

Figure 4 shows the magnetic field strength dependence of apparent viscosity and shear stress of MR grease at different temperature. In Figure 4 (a), apparent viscosity increases rapidly at the beginning stage and reaches saturation with the increase of magnetic field, and this phenomenon is more obvious under higher temperature. Furthermore, compared with higher external magnetic field, apparent viscosity is more sensitive to temperature at lower magnetic field, which is consistent with the results observed in Figure 2. From figure 4(b), shear stress presents an

\begin{tabular}{|l|}
\hline Formatted: Font: (Default) Cambria Math \\
\hline Formatted: Font: (Default) Times New Roman \\
\hline Formatted: Font: (Default) Cambria Math \\
\hline Formatted: Font: (Default) Times New Roman \\
Formatted: Font: (Default) Cambria Math \\
\hline Formatted: Font: (Default) Cambria Math \\
Formatted: Font: (Default) Cambria Math \\
\hline
\end{tabular}

Formatted: Font: (Default) Times New Roman Formatted: Font: (Default) Times New Roman 
analogous parabolic increase with magnetic field at first and then tends to a plateau. In addition, when the magnetic field strength is below $700 \mathrm{kA} / \mathrm{m}$, shear stress reduces along temperature. With the further increase of the magnetic field, shear stress decrease first and then increase with temperature.
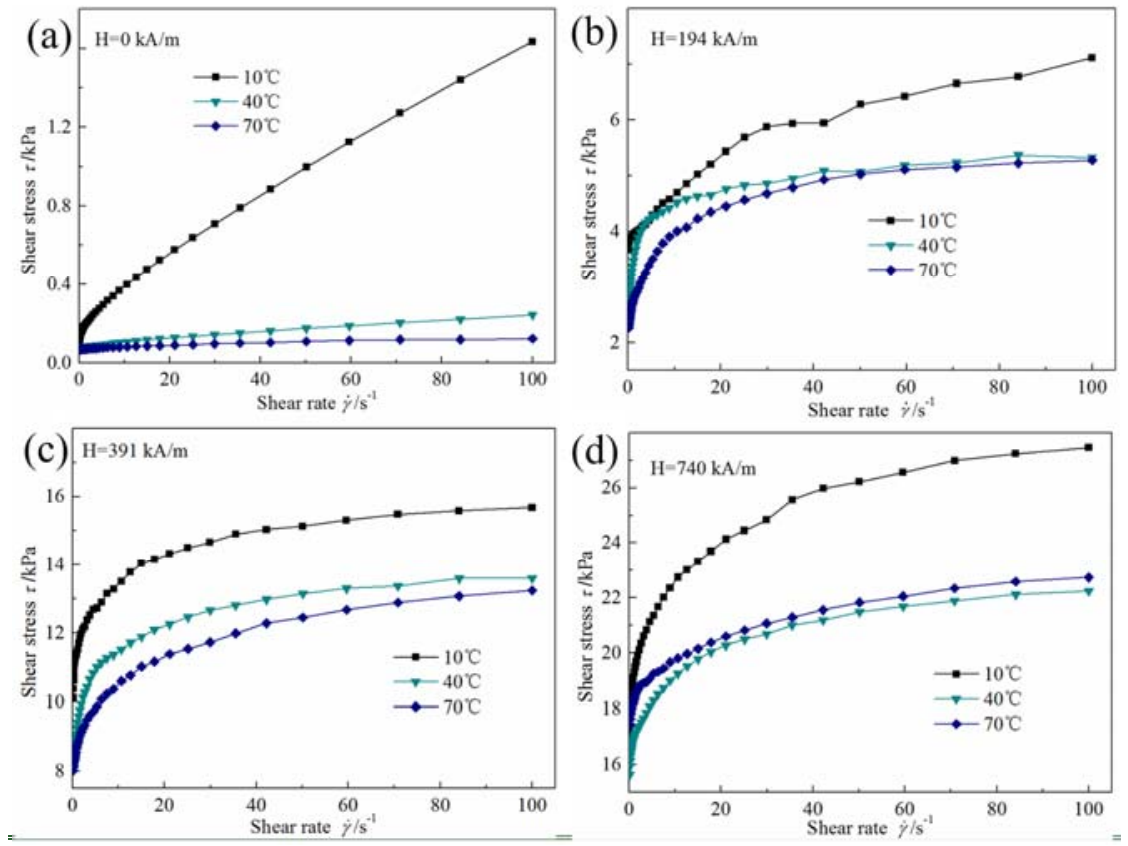

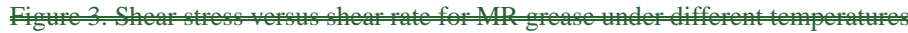
(a) $\mathrm{H}=0 \mathrm{kA} / \mathrm{m} ;(\mathrm{b}) \mathrm{H}=194 \mathrm{kA} / \mathrm{m} ;(\mathrm{C}) \mathrm{H}=391 \mathrm{kA} / \mathrm{m} ;(\mathrm{d}) \mathrm{H}=740 \mathrm{kA} / \mathrm{m}$
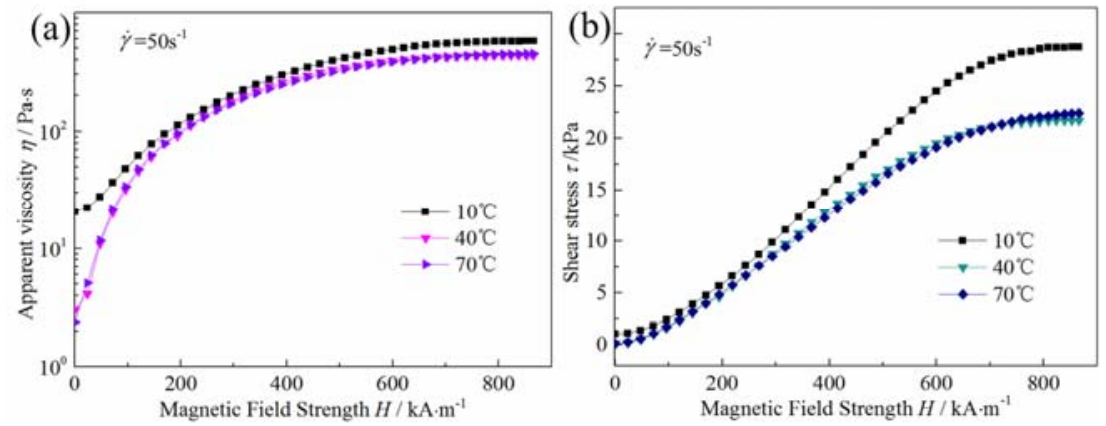

Figure 4.Apparent viscosity (a) and shear stress (b) versus magnetic field strength under different temperatures

In this study, the Bingham-plastic model was used to characterize the plastic flow stage of MR grease under different magnetic field and temperature. This is a generalized model for visco-plastic flow with yield stress. The model is defined as ${ }^{[35,36]}$ : 


$$
\left\{\begin{array}{cc}
\tau=\tau_{y}+\eta_{p} \dot{\gamma} & |\tau| \geq \tau_{y} \\
\dot{\gamma}=0 & |\tau|<\tau_{y}
\end{array}\right.
$$

where $\tau$ and $\dot{\gamma}$ represent the shear stress and shear rate, respectively. $\tau_{y}$ is yield stress as a function of magnetic field and $\eta_{p}$ is the plastic viscosity. In this work, $\tau_{y}$ was obtained by fitting Bingham-plastic model to flow curves of MR grease under different magnetic field and temperature when $\dot{\gamma}$ is higher than $35 \mathrm{~s}^{-1}$. An example of this fit is shown in figure 5 for MR grease at $40^{\circ} \mathrm{C}$ under different magnetic field strength.
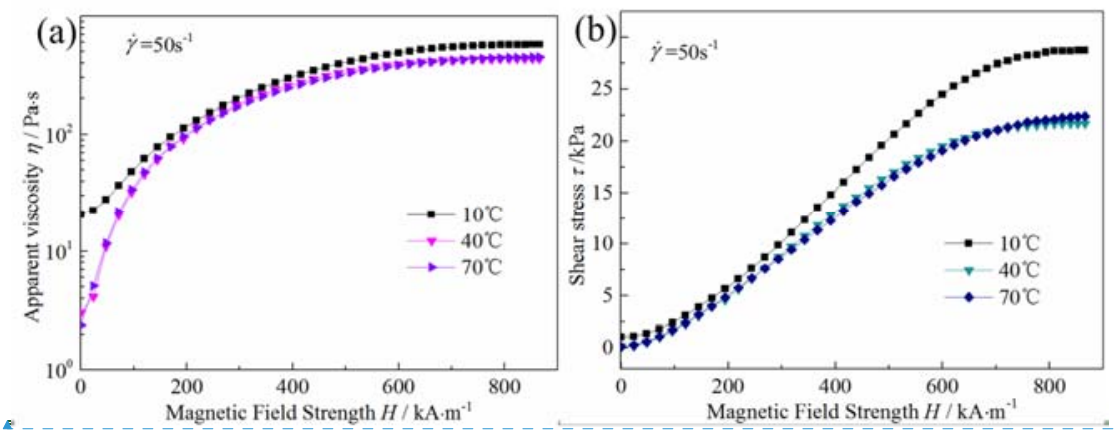

Fio 4. APP temperatures

Figure 6 shows the change of maximum yield stress along temperature under different magnetic field strengths. Apparently, magnetic field has significant impact on the maximum yield stress. In zero-field condition, maximum yield stress decrease along temperature. When the external magnetic field is applied, maximum yield stress still reduces along temperature with a less pronounced way. except for the rang from $50^{\circ} \mathrm{C}$ to $60^{\circ} \mathrm{C}$. And interestingly, this variation trend of maximum yield stress with temperature is more pronounced at higher field, which is different from the MR fluid ${ }^{[31]}$ whose maximum yield stress reduces along with the increase of temperature. The most possible reason is that, for MR grease, the stable column-like structures are formed as temperature increase to $60^{\circ} \mathrm{C}$.

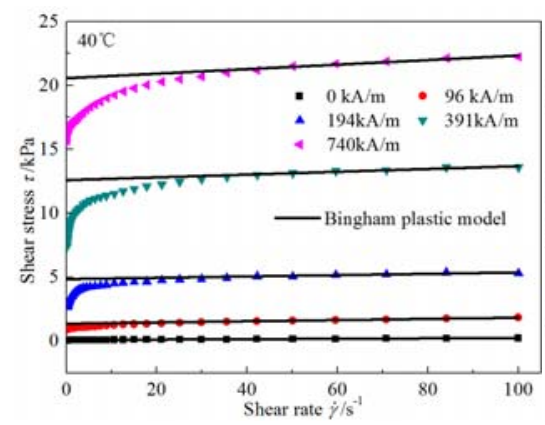

Figure 5. Experimental flow curves of MR grease at $40^{\circ} \mathrm{C}$ under different magnetic field strengths with the Bingham-plastic model fitting . $_{\text {}}$

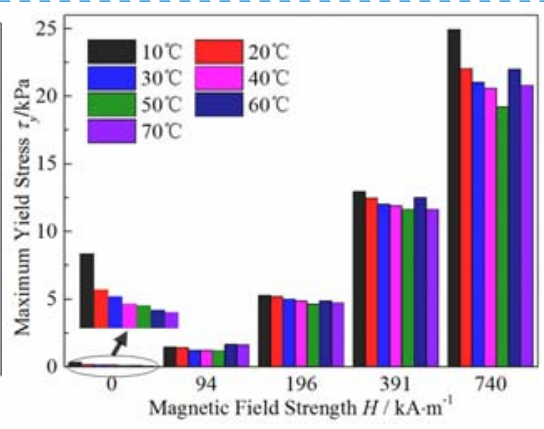

Figure 6. Maximum yield stress vs magnetic field strengths under different temperature
Field Code Changed

Formatted: Font: $10.5 \mathrm{pt}$
Formatted: Font: $10.5 \mathrm{pt}$
Field Code Changed
Field Code Changed
Formatted: Font: $10.5 \mathrm{pt}$
Formatted: Font: (Default) Times New Roman, $10.5 \mathrm{pt}$
Formatted: Font: $10.5 \mathrm{pt}$

Formatted: Font: $10.5 \mathrm{pt}$

Formatted: Font: $10.5 \mathrm{pt}$

Formatted: Font: $10.5 \mathrm{pt}$

Formatted: Font: $10.5 \mathrm{pt}$

Formatted: Font: $10.5 \mathrm{pt}$

Formatted: Font: $10.5 \mathrm{pt}$

Formatted: Font: (Default) Times New Roman

Formatted: Font: $10.5 \mathrm{pt}$

Formatted: Font: $10.5 \mathrm{pt}$

Formatted: Font: $10.5 \mathrm{pt}$

Formatted: Font: (Default) Times New Roman, 10.5 pt

Formatted: Font: $10.5 \mathrm{pt}$

Formatted: Font: (Default) Times New Roman 
3.3 Rheology in oscillatory shear

\subsubsection{Amplitude sweep}
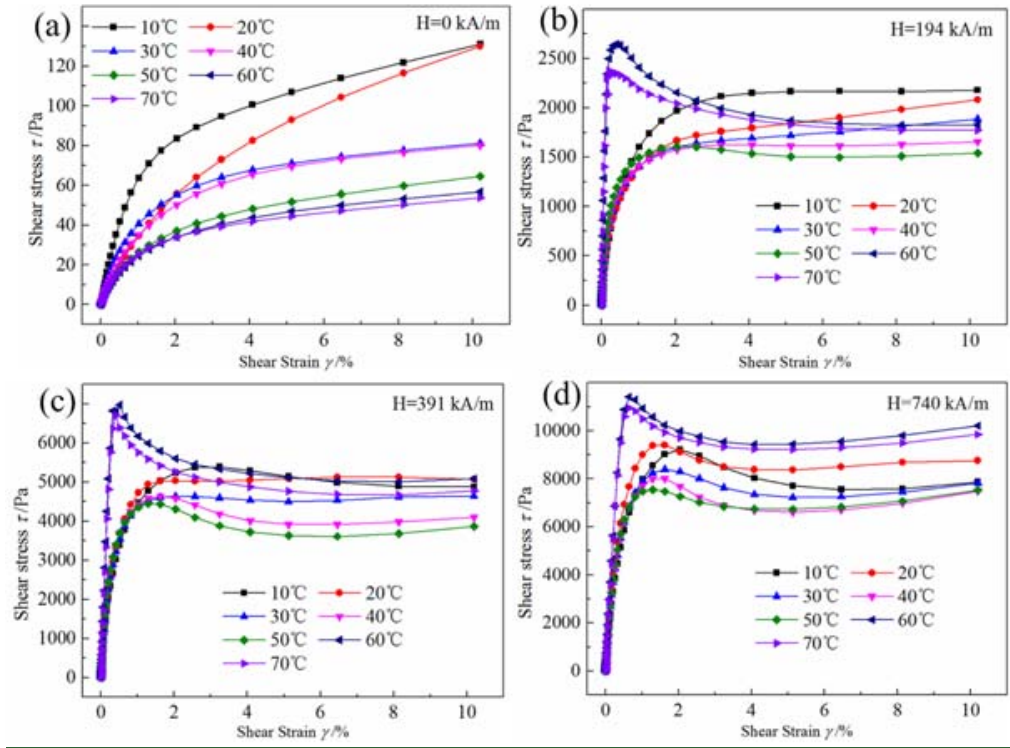

Figure 7. The shear stress vs strain curves of MR grease under different temperature(a) $\mathrm{H}=0 \mathrm{kA} / \mathrm{m} ;(\mathrm{b}) \mathrm{H}=194$

\section{$\mathrm{kA} / \mathrm{m} ;(\mathrm{c}) \mathrm{H}=391 \mathrm{kA} / \mathrm{m} ;(\mathrm{d}) \mathrm{H}=740 \mathrm{kA} / \mathrm{m}$}

The shear stress-strain curves of MR grease with different temperatures and magnetic field strengths under oscillatory shear are presented in figure 7. In the absence of magnetic field, shear stress demonstrates steady and sharp increase at the beginning and eontinues-saturates the linear increase with the enlargement of shear strain. Under the magnetic field strength of $194 \mathrm{kA} / \mathrm{m}$, shear stress shows a stiffer linear increase at first and then reaches a plateau along shear strain in the temperature range from $10^{\circ} \mathrm{C}$ to $50^{\circ} \mathrm{C}$. With the temperature up to $60^{\circ} \mathrm{C}$, shear stress peaks after a sudden increase at the beginning, then declines and stabilizes with the increasing of shear strain. When the external magnetic field strength increases to $740 \mathrm{kA} / \mathrm{m}$, shear stress peaks at the beginning of the shear strain for all tested temperature ranges. These phenomena indicate that the hindrance of the grease matrix to the chain formation of the particles reduces along with the increase of temperature and magnetic field. Besides, it can also be seen from the figure 7 that shear stress decreases along temperature without magnetic field. It is noticed that the shear stress of the MR grease at $740 \mathrm{kA} / \mathrm{m}$ reaches peak and then reduces for all temperatures. This phenomenal does not repeat in the low magnetic field strengths, i.e. $194 \mathrm{kA} / \mathrm{m}$ and $391 \mathrm{kA} / \mathrm{m}$. Unlike MR fluids where a low viscosity of the matrix is valid, for grease matrix, the large matrix viscosity has more impact on the rheological properties. With the increase of the temperature, the viscosity of the matrix reduces which benefits the MR effect, i.e. formation of the chain structure. These phenomena indicate that the hindrance of the grease matrix to the chain formation of the particles reduces along with the increase of temperature. In the presence of magnetic field, shear stress still decreases within the temperature range from $10^{\circ} \mathrm{C}$ to $50^{\circ} \mathrm{C}$, and afterwards, shear stress suddenly increases as the temperature increase to $60^{\circ} \mathrm{C}$. Finally, shear stress reduces again along temperature in the range of $60^{\circ} \mathrm{C}$ to $70^{\circ} \mathrm{C}$. 

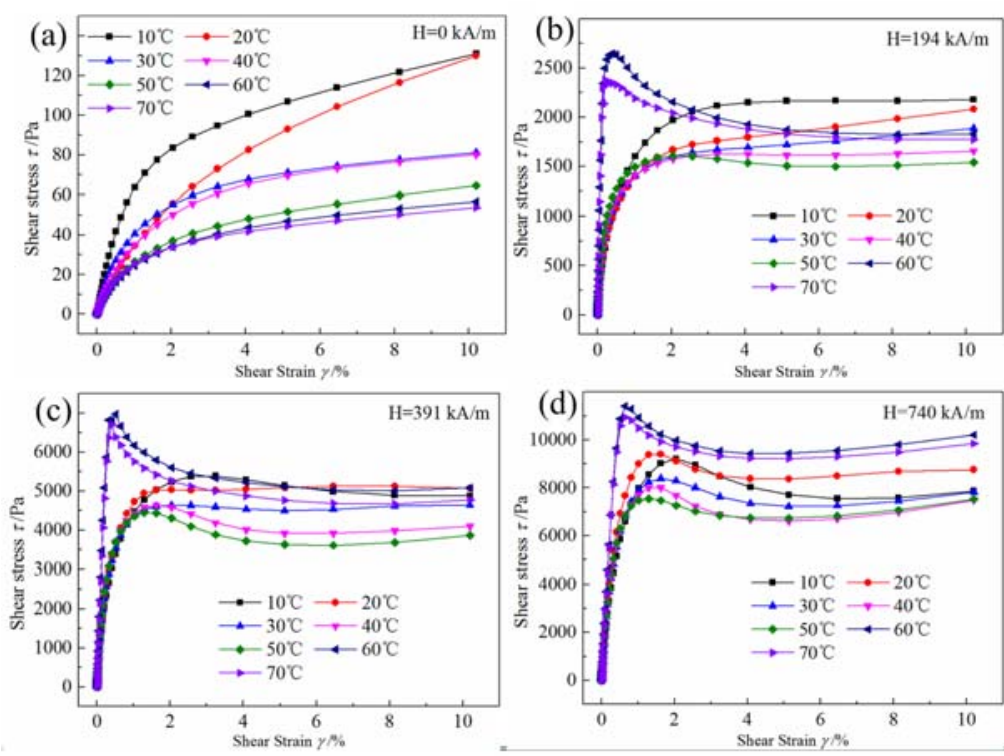

Figure 7. The shear stress vs strain curves of MR grease under different temperature(a)H=0 $\mathrm{kA} / \mathrm{m}$;(b)H=194 $\mathrm{kH} / \mathrm{m} ;(\mathrm{C}) \mathrm{H}=391 \mathrm{kA} / \mathrm{m} ;(\mathrm{d}) \mathrm{H}=740 \mathrm{kA} / \mathrm{m}$
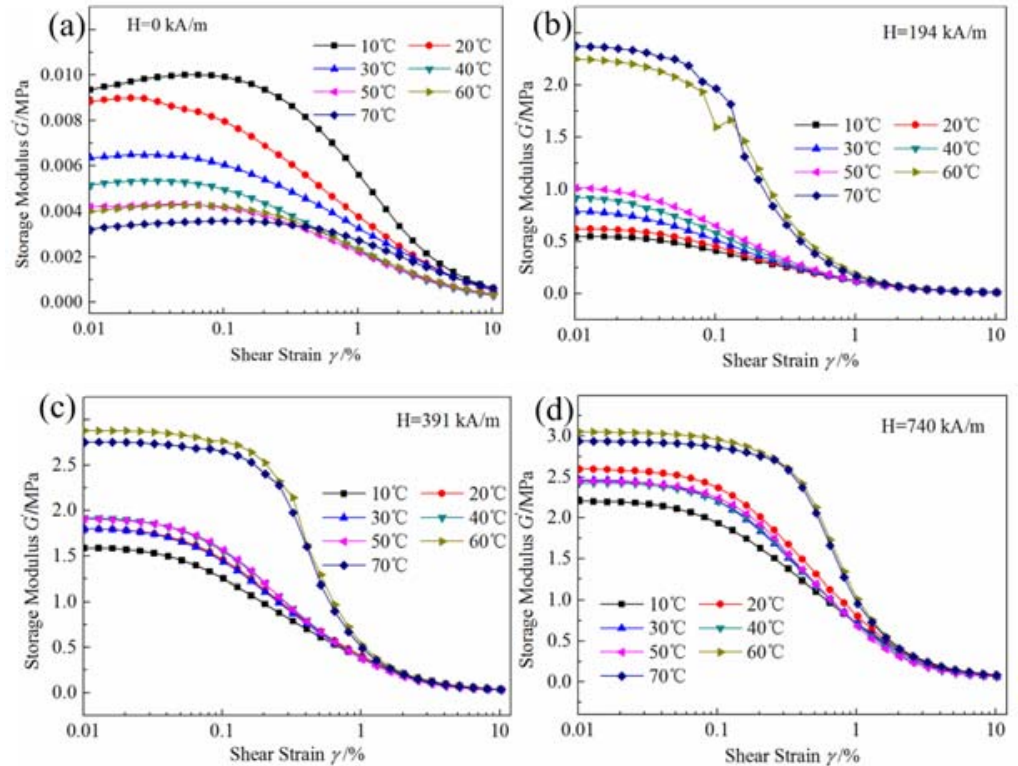

Figure 8. The strain amplitude dependence of MR grease on the storage modulus under different temperatures (a)H=0 kA/m;(b)H=194 kA/m;(c)H=391 kA/m;(d)H=740 kA/m

Storage modulus G' and loss modulus G” are two important parameters to characterize viscoelastic materials. Storage modulus is a measure of the deformation energy stored in the sample during shear, this energy is completely available after the external load is removed ${ }^{[14,37]}$. 
Figure 8 shows the storage modulus of MR grease at different temperatures under the magnetic field strength of $0 \mathrm{kA} / \mathrm{m}, 193 \mathrm{kA} / \mathrm{m}, 391 \mathrm{kA} / \mathrm{m}, 740 \mathrm{kA} / \mathrm{m}$, obtained from the amplitude sweep test. Along with the increase of shear strain, storage modulus always reduces at different temperatures and magnetic field strength. In addition, it can be also seen from figure 8 that the storage modulus decreases along temperature without magnetic field. By contrast, when the magnetic field is applied, the temperature increment of MR grease will cause the increase in storage modulus, and interestingly enough, temperature has an obvious impact at lower shear strain but has nearly minimum impact when the shear strain is above $10 \%$ without magnetic field or $1 \%$ with magnetic field. It is s's also worth mentioning that, at lower magnetic field level, the temperature makes big difference on the storage modulus in the range of $50{ }^{\circ} \mathrm{C} \mathrm{A}_{\Delta}$ to $60_{\Delta}^{\circ} \mathrm{C}$, when the temperature increases from $50{ }^{\circ} \mathrm{C}_{\Delta}$ to $60_{\mathrm{A}}^{\circ} \mathrm{C}$, the storage modulus at $\gamma=0.01 \%$ and $\mathrm{H}=194 \mathrm{kA} / \mathrm{m}$ increase from $1.02 \mathrm{MPa}$ to $2.25 \mathrm{MPa}$, up $121 \%$. With the further increase of magnetic field, the gap becomes smaller, e.g. $24 \%$ increase at $\gamma=0.01 \%$ and $\mathrm{H}=740 \mathrm{kA} / \mathrm{m}$. The results indicate that the effect of temperature on the storage modulus of MR grease gradually decreases with increasing magnetic field.
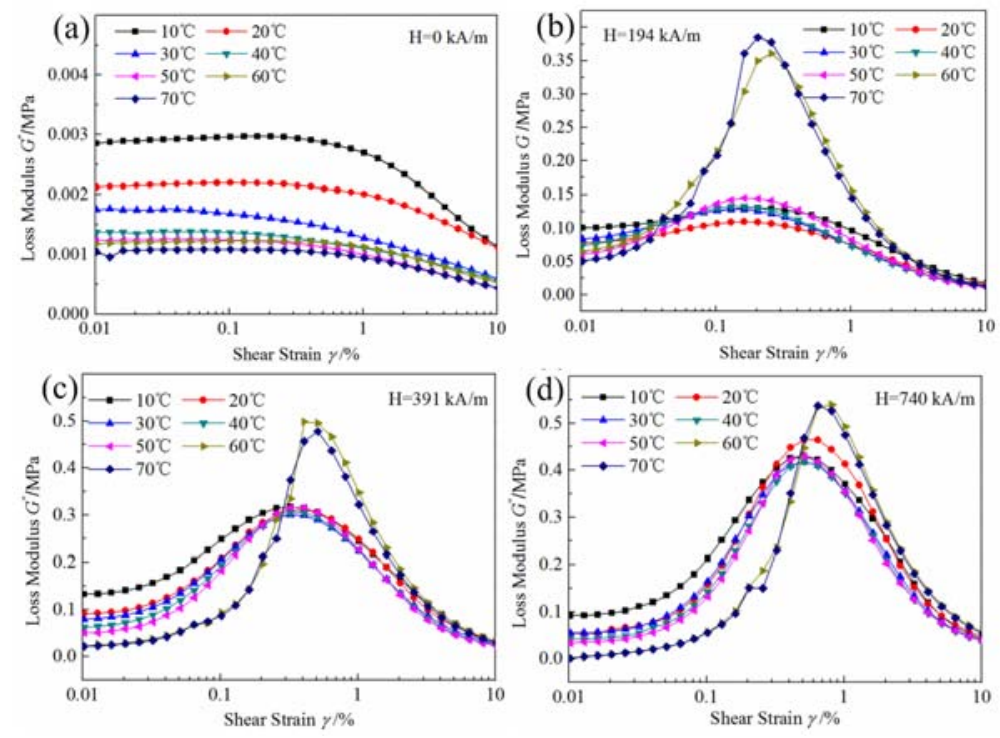

Figure 9.the strain amplitude dependence of MR grease on the loss modulus under different temperatures (a)H=0 kA/m;(b)H=194 kA/m;(c)H=391 kA/m;(d)H=740 kA/m

As known, loss modulus is a measure of information on energy dissipation ${ }^{\mathrm{f}}$ dissipation $^{[14,37]}$. The relationship between loss modulus and strain amplitude at different temperature and magnetic field for MR grease is shown in Figure 9. In the absence of a magnetic field, the loss modulus remains nearly constant when shear strain is lower than $0.4 \%$. When the magnetic field is applied, the loss modulus peaks at medium strain amplitude and the peak values gradually increase with the increase of magnetic field, i.e. $0.2 \%, 0.6 \%$ and $0.8 \%$ for $194 \mathrm{kA} / \mathrm{m}, 391 \mathrm{kA} / \mathrm{m}$ and $740 \mathrm{kA} / \mathrm{m}$, respectively. This is because the energy dissipation mainly comes from the interaction between the magnetic particles and the soap fibers of grease matrix. The interaction between them will reaches the maximum due to the microstructure of MR grease under magnetic field was destroyed at the peak value of strain amplitude. Moreover, we can also conclude from figure 9 that loss modulus
Formatted: Font: (Default) Times New Roman

Formatted: Font: (Default) Times New Roman

Formatted: Font: (Default) Times New Roman

Formatted: Font: Cambria Math

Formatted: Font: (Default) Times New Roman

Formatted: Font: Cambria Math

Formatted: Font: Times New Roman

Formatted: Font: Cambria Math

Formatted: Font: Times New Roman

Formatted: Font: (Default) Cambria Math

Formatted: Font: (Default) Times New Roman

Formatted: Font: (Default) Times New Roman

Formatted: Font: (Default) Times New Roman

Formatted: Font: (Default) Times New Roman

Formatted: Font: (Default) Times New Roman

Formatted: Font: (Default) Times New Roman

Formatted: Font: (Default) Times New Roman 
reduces along temperature under the zero-field condition. On the other hand, in the presence of magnetic field, the loss modulus decreases along temperature at lower strain amplitude but increases along temperature at high strain amplitude.

\subsubsection{Frequency sweep}

In addition to the strain amplitude, driving frequency is also an important factor influencing the dynamic rheological performance of MR grease. The frequency sweep mode was applied to MR grease at a fixed strain amplitude $\gamma=0.01 \%$ and the frequency was swept from $1 \mathrm{~Hz}$ to100 $\mathrm{Hz}$. Figure 10 shows the storage modulus as a function of frequency at different temperatures and magnetic field strengths. At the case of no-field, storage modulus has high frequency dependency and increases along frequency. However, the frequency dependence of storage modulus nearly disappearsed except for lower frequency range under the magnetic field. This interesting experimental result may be related to the changes in microstructure of lithium-based grease matrix. From figure 10, storage modulus is also strongly dependent on temperature, which decreases along temperature at the no-field case and increase along temperature under the magnetic field. Besides, similar to the result of amplitude sweep, temperature also makes big difference on the storage modulus in the range of $50^{\circ} \mathrm{C}$ to $60^{\circ} \mathrm{C}_{\Delta}$ under the frequency sweep test.
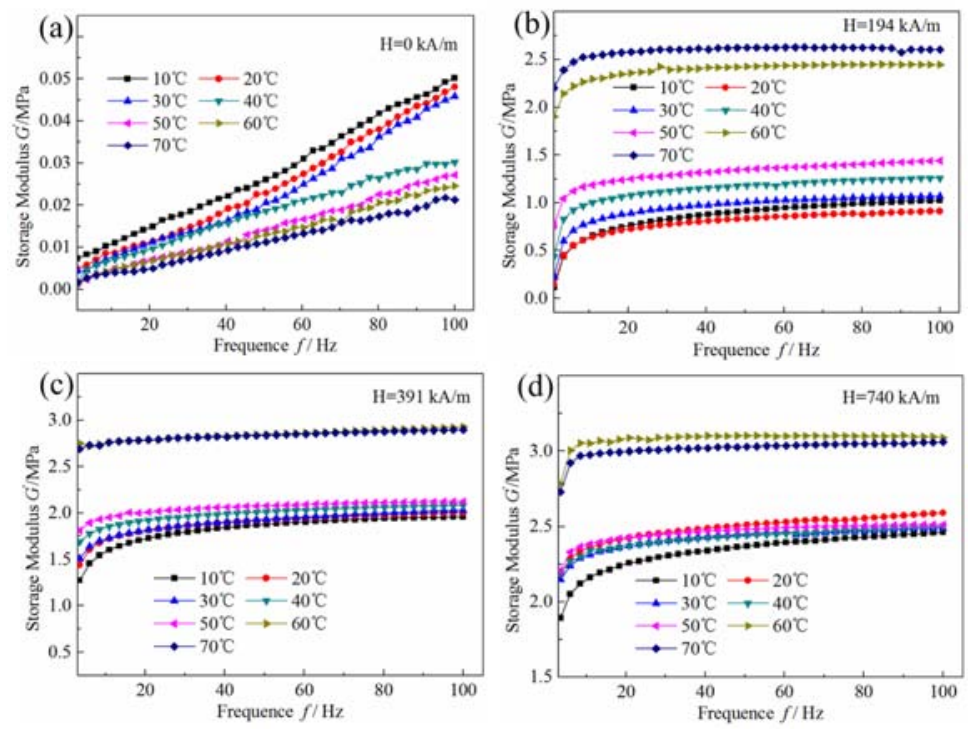

Figure 10. Storage modulus-frequency plots of MR grease under different temperatures (a)H=0 kA /m;(b)H=194 kA /m;(c)H=391 kA /m;(d)H=740 kA /m
Formatted: Font: (Default) Times New Roman

Formatted: Font: (Default) Times New Roman

Formatted: Font: (Default) Times New Roman 

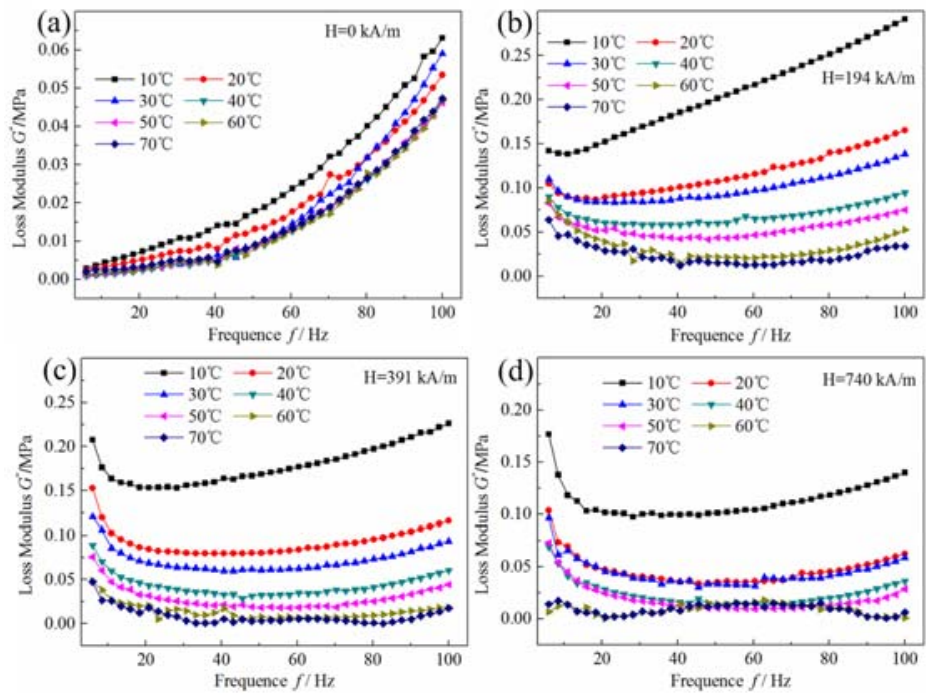

Figure 11. Loss modulus-frequency plots of MR grease under different temperatures

(a)H=0 kA/m;(b)H=194 kA/m;(c)H=391 kA/m;(d)H=740 kA/m

Figure 11 shows the change of loss modulus with sweep frequency at different magnetic field strengths and temperatures. From figure 11(a), we can find that loss modulus has frequency dependency and increases along with the frequency when the magnetic field is not applied. In the presence a magnetic field, the loss modulus of MR grease decreases first and then increases slowly with the increase of sweep frequency, and the transition of two trends gradually moves to higher frequency with the increase of temperature. Furthermore, at a fixed frequency, the loss modulus decreases along temperature with magnetic field. Besides, by comparing the values of the storage modulus, G' , and the loss modulus, G”, in the whole frequency range, it can be concluded that the lithium-based MR grease exhibits stronger elastic properties than viscous properties.

\subsubsection{Magnetic field sweep}
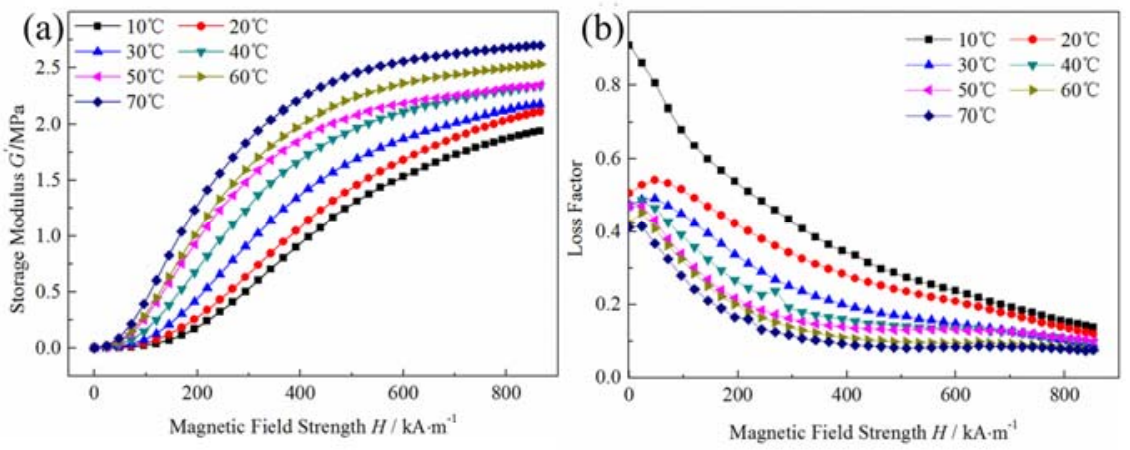

Figure12.Storage modulus (a) and loss factor (b) as a function of magnetic field strength under different temperatures (the actuating strain amplitude and frequency was set as $0.01 \%$ and $5 \mathrm{~Hz}$, respectively).

The magnetic field strength dependence of storage modulus and loss factor at different temperatures in small strain (linear viscoelastic range) was shown in figure 12. In figure 12 (a), the 
storage modulus shows an increasing tendency with magnetic field before reaching magnetic saturation at high field strength. On the other hand, when the magnetic field was kept constant, storage modulus increases with temperature rising, which is in contrast to the decrease in storage modulus of MR elastomers ${ }^{[38,39]}$ and MR plastomer ${ }^{[40]}$ with the increase of temperature. This is because the CI particles of the MR elastomer are fixed in the matrix. When the magnetic field is fixed, the temperature dependence of storage modulus is mainly determined by the rubber matrix. The higher the temperature, the softer the rubber matrix, then the storage modulus decreases accordingly. However, for MR grease, the CI particles in grease matrix could move along the direction of the magnetic field to form a chain structure. When the temperature rises, the hindrance of grease matrix to the chain formation of the particles will be reduced, resulting in an increase in the storage modulus of MR grease with the temperature increase at a fixed magnetic field strength.

The definition of the loss factor is the ratio of loss modulus to storage modulus, which is an important parameter that reflects the damping properties of the material ${ }^{[41,42]}$. As can be seen in figure 12 (b), at the temperature of $10^{\circ} \mathrm{C}$, , loss factors of MR grease shows a descending trend with the increase in magnetic field strength. When the temperature is higher than $20^{\circ} \mathrm{C}$, loss factors first increases slightly and then reach its maximum value before decreasing with magnetic field strength. In addition, loss factor decreases with the temperature and the trend of this change become very negligible at high field strength. As known, loss factor is related to the energy dissipation of the material, which mainly comes from the interaction among different inner $\underline{\text { structures }}^{[33]}$. For MR grease, energy dissipation mainly determined by the interaction between CI particles and grease matrix, which is equal to interaction force multiplied by the slipping displacement ${ }^{[44]}$. In the initial stage when applying the magnetic field, the formation of particle chains greatly enhances the interaction force between CI particles and grease matrix. Although the sliding displacement becomes smaller at this time, the dissipated energy still increases. Hence, the loss factor of MR grease macroscopically increased by the magnetic field. With the magnetic field further increased, sliding displacement between CI particles and grease matrix drastically decreases due to the strong interaction force. Then, the energy dissipation is reduced and the loss factor is decreased with the increase of magnetic field.
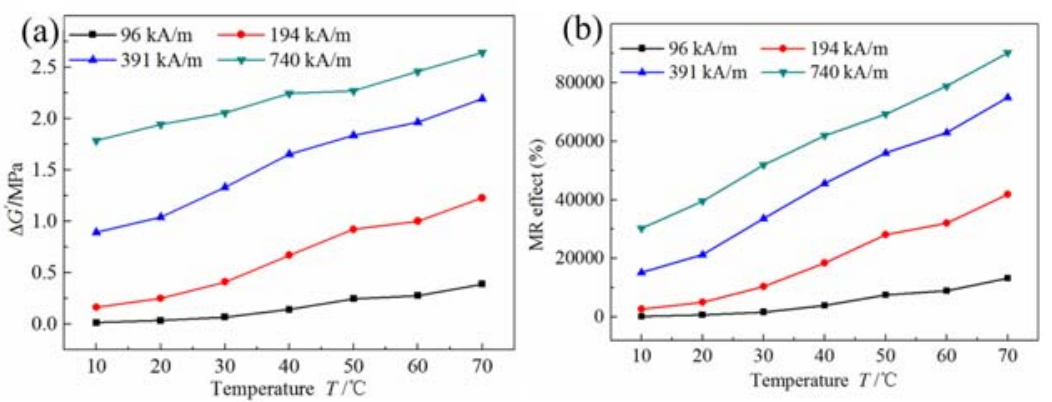

Figure13.Magneto-induced modulus (a) and Relative MR effect (b) as a function of temperature under different magnetic field strengths 
Table 1. The initial storage modulus, maximum magneto-induced modulus and maximum MR effect of MR grease under different temperatures

\begin{tabular}{|c|c|c|c|}
\hline $\begin{array}{c}\text { Temperature } \\
T\left({ }^{\circ} \mathrm{C}\right)\end{array}$ & $\begin{array}{l}\text { Initial storage modulus } \\
\qquad G_{0}^{\prime}(K P a)\end{array}$ & $\begin{array}{l}\text { Maximum magneto-induced modulus } \\
\qquad \Delta G_{\max }^{\prime}(\mathrm{KPa})\end{array}$ & $\begin{array}{l}\text { Maximum MR effect } \\
\Delta G_{\max }^{\prime} / G_{0}^{\prime} \times 100 \%\end{array}$ \\
\hline 10 & 5.9 & 1786.5 & $30280 \%$ \\
\hline 20 & 4.91 & 1945.8 & $39629 \%$ \\
\hline 30 & 3.96 & 2057.1 & $51947 \%$ \\
\hline 40 & 3.63 & 2245.7 & $61865 \%$ \\
\hline 50 & 3.28 & 2274.6 & $69348 \%$ \\
\hline 60 & 3.12 & 2462.1 & $78913 \%$ \\
\hline 70 & 2.93 & 2646.6 & $90328 \%$ \\
\hline
\end{tabular}

Figure13 shows the temperature dependence of Magneto-induced modulus and MR effect under different magnetic field strength. Magneto-induced modulus, $\triangle G$, is defined as the difference between storage modulus, $G^{\prime}$, and initial storage modulus, $\mathrm{G}_{0}$ '. MR effect is the ratio of magneto-induced modulus to initial storage modulus. It can be seen from the figure11 that, in accordance with the changing trends of storage modulus, both magneto-induced modulus and MR effect are increase with increasing temperature and magnetic field strength. The results indicate that the increase of the temperature will enhance the modulus of MR grease itself, which is of great significance to the practical application of MR grease.

The initial storage modulus, maximum magneto-induced modulus and maximum MR effect of MR grease under different temperature was shown in table 1 . When the temperature increase from $10^{\circ} \mathrm{C}$ to $70^{\circ} \mathrm{C}$, the maximum magneto-induced modulus increase from $1786.5 \mathrm{KPa}$ to 2646.6 $\mathrm{KPa}$, which is almost $48 \%$ increase. In addition, Maximum MR effect has reached $90328 \%$ at the temperature of $70^{\circ} \mathrm{C}$, which is higher than the MR effect of any other MR materials reported previously ${ }^{[9,12,40]}$. The main reason for this phenomenon is that the grease with NLGI0 is chosen as the MR grease matrix, resulting a lower initial storage modulus of MR grease.

\section{Conclusion}

In this paper, MR grease with 70\% weight fraction of carbonyl iron was prepared by mixing the CI particles and commercial grease using a mechanical stirrer.; and- $\underline{T}$ the effect of temperature (ranging from $10^{\circ} \mathrm{C}$ to $70^{\circ} \mathrm{C}$ ) on the rheological properties of MR grease weasre investigated under steady and oscillatory shear tests, respectively. Under steady shear test, it is found that the effect of temperature on apparent viscosity becomes smaller and smallerreducing with the increase of magnetic field strength. Besides, unlike the decrease in the maximum yield stress of MR fluid with increasing temperature, in the presence of magnetic field, maximum yield stress exhibitgets an increase trend as temperature increase from $50_{A}^{\circ} \mathrm{C}$ to $60_{\Delta}^{\circ} \mathrm{C}$, and the-increasing trend is more pronounced at higher magnetic field comparzed ble-to lower field. For the oscillatory shear test of amplitude sweep test, , temperature has an obvious impact on storage modulus at lower shear strain but has nearly minimum impact when the shear strain is above $10 \%$ without magnetic field or $1 \%$ with magnetic field. Loss modulus reduces along temperature under the zero-field condition, while in the presence of magnetic field, the loss modulus decreases along temperature at lower strain amplitude but increases along temperature at high strain amplitude. Under the oscillatory shear

\begin{tabular}{l} 
Formatted Table \\
$\begin{array}{l}\text { Formatted: Space Before: } 0 \mathrm{pt}, \text { After: } 0 \mathrm{pt} \text {, Line spacing: } \\
\text { single }\end{array}$ \\
\hline Field Code Changed \\
Field Code Changed \\
$\begin{array}{l}\text { Formatted: Space Before: } 0 \mathrm{pt}, \text { After: } 0 \mathrm{pt} \text {, Line spacing: } \\
\text { single }\end{array}$ \\
$\begin{array}{l}\text { Formatted: Space Before: } 0 \mathrm{pt}, \text { After: } 0 \mathrm{pt} \text {, Line spacing: } \\
\text { single }\end{array}$ \\
$\begin{array}{l}\text { Formatted: Space Before: } 0 \mathrm{pt}, \text { After: } 0 \mathrm{pt} \text {, Line spacing: } \\
\text { single }\end{array}$ \\
$\begin{array}{l}\text { Formatted: Space Before: } 0 \mathrm{pt}, \text { After: } 0 \mathrm{pt} \text {, Line spacing: } \\
\text { single }\end{array}$ \\
$\begin{array}{l}\text { Formatted: Space Before: } 0 \mathrm{pt}, \text { After: } 0 \mathrm{pt} \text {, Line spacing: } \\
\text { single }\end{array}$ \\
$\begin{array}{l}\text { Formatted: Space Before: } 0 \mathrm{pt}, \text { After: } 0 \mathrm{pt} \text {, Line spacing: } \\
\text { single }\end{array}$ \\
$\begin{array}{l}\text { Formatted: Space Before: } 0 \mathrm{pt} \text {, After: } 0 \mathrm{pt} \text {, Line spacing: } \\
\text { single }\end{array}$ \\
\hline
\end{tabular}

Formatted: Font: (Default) Cambria Math

Formatted: Font: (Default) Cambria Math 
test of frequency sweep, storage modulus and loss modulus are allatse strongly dependent on temperature. Furthermore, it can be seen from the magnetic field sweep test that the enhancement of temperature resultsed in the increase of storage modulus and the reduction of the loss factor, which indicates that the increase of temperature enhances the MR performance. The reason for the rheological changes of the MR grease under different temperature is attributed to the microstructural variation of Lithium-based grease matrix.

\section{Acknowledgments}

This work has been supported by a Natural Science Foundation of China (NSFC) grant funded by the Chinese government (No. 51675280 and No. 51705467).

\section{References}

[1]. Kintz K A, Carlson J D, Munoz B C, et al. Magnetorheological grease composition: U.S. Patent 6,547,986. 2003-4-15.

[2]. Ji E K, Ko J D, Liu Y D, et al. Effect of Medium Oil on Magnetorheology of Soft Carbonyl Iron Particles. IEEE Transactions on Magnetics, 2012, 48(11):3442-3445.

[3]. Sahin H, Gordaninejad F, Wang X, et al. Rheological behavior of magneto-rheological grease (MRG). The International Symposium On: Smart Structures and Materials \& Nondestructive Evaluation and Health Monitoring. International Society for Optics and Photonics, 2007.

[4]. Mohamad N, Mazlan S A, Imaduddin F, et al. A comparative work on the magnetic field-dependent properties of plate-like and spherical iron particle-based magnetorheological grease. PloS one, 2018, 13(4): e0191795.

[5].Ashtiani M, Hashemabadi S H, Ghaffari A. A review on the magnetorheological fluid preparation and stabilization. Journal of Magnetism \& Magnetic Materials, 2015, 374:716-730.

[6].Shah K, Phu D X, Seong M S, et al. A low sedimentation magnetorheological fluid based on plate-like iron particles, and verification using a damper test. Smart Materials \& Structures, 2014, 23(2):027001 (10pp).

[7].Sun S S, Yang J, Li W H, et al. Development of an isolator working with magnetorheological elastomers and fluids. Mechanical Systems \& Signal Processing, 2016, 83:371-384.

[8].Li Y, Li J, Li W, Samali B.et al. Development and characterization of a magnetorheological elastomer based adaptive seismic isolator. Smart Materials \& Structures, 2013, 22(3):36-46.

[9].Wang Y, Gong X, Yang J, et al. Improving the Dynamic Properties of MRE under Cyclic Loading by Incorporating Silicon Carbide Nanoparticles. Industrial \& Engineering Chemistry Research, 2014, 53(8):3065 $-3072$.

[10]. Yang P, Yu M, Fu J, et al. Rheological properties of dimorphic magnetorheological gels mixed dendritic carbonyl iron powder. Journal of Intelligent Material Systems and Structures, 2018, 29(1): 12-23.

[11]. Wei B, Gong X, Jiang W, et al. Study on the properties of magnetorheological gel based on polyurethane. Journal of Applied Polymer Science, 2010, 118(5):2765-2771.

[12]. Rankin P J, Horvath A T, Klingenberg D J. Magnetorheology in viscoplastic media. Rheologica Acta, 1999, 38(5):471-477.

[13]. Mohamad N, Mazlan S A, Ubaidillah, et al. The Field-Dependent Rheological Properties of Magnetorheological Grease Based on Carbonyl-Iron-Particles. Smart Material Structures, 2016, 25(9):10.

[14].Park J H, Kwon M H, Park O O. Rheological properties and stability of magnetorheological fluids using viscoelastic medium and nanoadditives. Korean Journal of Chemical Engineering, 2001, 18(5):580-585. 
[15].Park B O, Park B J, Hato M J, et al. Soft magnetic carbonyl iron microsphere dispersed in grease and its rheological characteristics under magnetic field. Colloid \& Polymer Science, 2011, 289(4):381-386.

[16].Sahin H, Wang X, Gordaninejad F. Temperature Dependence of Magneto-rheological Materials. Journal of Intelligent Material Systems \& Structures, 2009, 20(18):2215-2222.

[17].Sahin H, Wang X, Gordaninejad F. A new model for yield stress of magneto-rheological greases/gels under combined effects of magnetic field and temperature. 2009, 7288:72881E-72881E-9.

[18]. Delgado M A, Sánchez M C, Valencia C, et al. Relationship among microstructure, rheology and processing of a lithium lubricating grease. Chemical Engineering Research and Design, 2005, 83(9): 1085-1092.

[19]. Mas R, Magnin A. Rheology of colloidal suspensions: case of lubricating greases. Journal of Rheology, 1994, 38(4): 889-908.

[20]. Martín-Alfonso J E, Valencia C, Sánchez M C, et al. Evaluation of different polyolefins as rheology modifier additives in lubricating grease formulations. Materials Chemistry \& Physics, 2011, 128(3):530-538.

[21]. Lugt P M. Modern advancements in lubricating grease technology. Tribology international, 2016, 97: 467-477.

[22]. Sánchez M C, Franco J M, Valencia C, et al. Atomic force microscopy and thermo-rheological characterisation of lubricating greases. Tribology letters, 2011, 41(2): 463-470.

[23]. Madiedo J M, Franco J M, Valencia C, et al. Modeling of the Non-Linear Rheological Behavior of a Lubricating Grease at Low-Shear Rates. Journal of Tribology, 2000, 122(3):590-596.

[24].Martín-Alfonso J E, Valencia C, Sánchez M C, et al. Evaluation of thermal and rheological properties of lubricating greases modified with recycled LDPE. Tribology transactions, 2012, 55(4): 518-528

[25]. Läuger J, Heyer P. Temperature-Dependent Rheology and Tribology of Lubrication Greases Investigated with New Flexible Platform for Tribological Measurements on A Rheometer. Advanced Tribology. Springer, Berlin, Heidelberg, 2009: 61-63.

[26]. Delgado M A, Valencia C, Sánchez M C, et al. Thermorheological behaviour of a lithium lubricating grease. Tribology Letters, 2006, 23(1): 47-54.

[27]. Hurley S. Examination of grease structure by SEM and AFM techniques. NLGI spokesman, 2001, 65(5): 17.

[28]. Gonçalves D, Rui M, Graça B, et al. Formulation, rheology and thermal aging of polymer greases - Part II: Influence of the co-thickener content. Tribology International, 2015, 87:160-170.

[29]. Pan J, Cheng Y, Yang J. Structural Degradation of a Lithium Lubricating Grease after Thermal Ageing. Journal of Chemical Engineering of Japan, 2016, 49(7): 579-587.

[30]. Rabbani Y, Ashtiani M, Hashemabadi S H. An experimental study on the effects of temperature and magnetic field strength on the magnetorheological fluid stability and MR effect.. Soft Matter, 2015, 11(22):4453-4460.

[31]. Guerrerosanchez C, Ortizalvarado A, Schubert U S. Temperature effect on the magneto-rheological behavior of magnetite particles dispersed in an ionic liquid. 2009:012052.

[32]. Hayashi K, Sakamoto W, Yogo T. Magnetic and rheological properties of monodisperse $\mathrm{Fe}_{3} \mathrm{O}_{4}$ nanoparticle/organichybrid. Journal of Magnetism \& Magnetic Materials, 2009, 321(5):450-457.

[33]. Ido Y, Yokoyama H, Nishida H. Viscous and damping properties of magnetorheological fluids containing needle-like nonmagnetic particles. International Journal of Applied Electromagnetics \& Mechanics, 2016:1-7.

[34]. Rabbani Y, Ashtiani M, Hashemabadi S H. An experimental study on the effects of temperature and magnetic field strength on the magnetorheological fluid stability and MR effect. Soft Matter, 2015, 11(22):4453-4460.

[35]. Wereley N M, Chaudhuri A, Yoo J H, et al. Bidisperse magnetorheological fluids using Fe particles at nanometer and micron scale. Journal of Intelligent Material Systems \& Structures, 2006, 17(5):393-401.

[36].Gong X, Xu Y, Xuan S, et al. The investigation on the nonlinearity of plasticine-like magnetorheological material under oscillatory shear rheometry. Journal of Rheology, 2012, 56(56):1375. 
[37].Zhang W, Gong X, Xuan S, et al. Temperature-dependent mechanical properties and model of magnetorheological elastomers. Industrial \& Engineering Chemistry Research, 2011, 50(11): 6704-6712.

[38].Ju B, Tang R, Zhang D, et al. Temperature-dependent dynamic mechanical properties of magnetorheological elastomers under magnetic field. Journal of Magnetism and Magnetic Materials, 2015, 374: 283-288.

[39].Xu Y, Gong X, Xuan S, et al. A high-performance magnetorheological material: preparation, characterization and magnetic-mechanic coupling properties. Soft Matter, 2011, 7(11):5246-5254.

[40]. Yang P, Yu M, Fu J, et al. The damping behavior of magnetorheological gel based on polyurethane matrix. Polymer Composites, 2017, 38(7):1248-1258.

[41]. Gong X, Fan Y, Xuan S, et al. Control of the Damping Properties of Magnetorheological Elastomers by Using Polycaprolactone as a Temperature-Controlling Component. Industrial \& Engineering Chemistry Research, 2012, 51(18):6395 - 6403.

[42].Chandra R, Singh S P, Gupta K. Damping studies in fiber-reinforced composites-a review. Composites Structures, 1999, 46(1):41-51.

[43].Fan Y C, Gong X L, Jiang W Q, et al. Effect of maleic anhydride on the damping property of magnetorheological elastomers. Smart Materials \& Structures, 2010, 19(5):055015. 